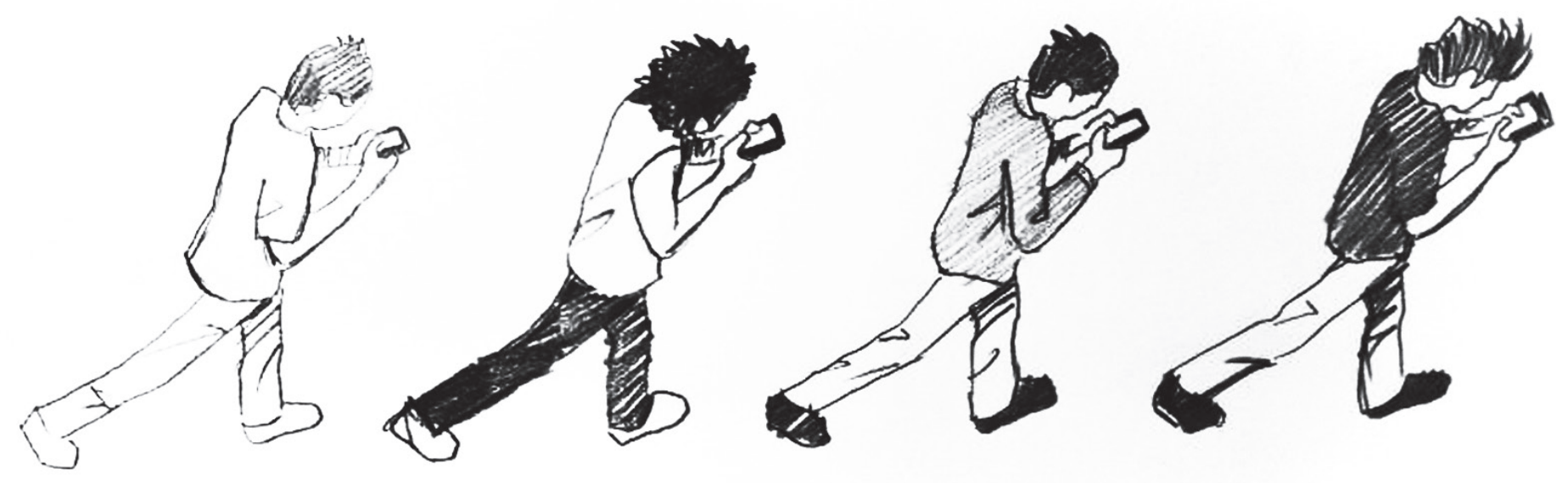

\title{
CULTURAS JUVENILES ENTRE EL CIBERESPACIO Y LA CULTURA ESCRITA
}

Por:

\section{YOUTH CULTURES BETWEEN THE CYBERSPACE AND THE WRITTEN CULTURE}

\section{Giovanna Carvajal Barrios ${ }^{1}$}

Profesora de la Escuela de Comunicación Social

Universidad del Valle, Cali, Colombia

giovanna.carvajal@correounivalle.edu.co

Resumen: El presente artículo constituye una aproximación al universo de las culturas juveniles; se propone abordar las implicaciones que tiene para dichas culturas el acceso al ciberespacio en el siglo XXI, así como reflexionar sobre las posturas que debemos asumir desde la institución escolar frente a la presencia de los protagonistas de las culturas juveniles en el ámbito educativo. En la primera parte se realiza una caracterización de ellas a partir de la investigación realizada por Marta Marín y Germán Muñoz (2002) sobre música y creación en las culturas juveniles; en la segunda parte se aborda la conceptualización del ciberespacio realizada por Pierre Lévy (2007), para intentar visualizar qué perspectivas se abren para las culturas juveniles a partir de la interconectividad generalizada del siglo XXI. Por último, se sugiere una serie de implicaciones que tiene para el trabajo pedagógico en las áreas de lectura y escritura el reconocer la participación de los estudiantes en distintas culturas juveniles.

Palabras clave: Culturas juveniles, ciberespacio, cultura escrita, educación. 
Abstract: This paper is an approach to the world of youth cultures; intends to address the implications that the access to cyberspace has for these cultures in the XXI century, and reflect on the positions that we must assume from the school system towards the presence of the protagonists of youth cultures in the educational context. In the first part a characterization of them is made from the research conducted by Marta Marín and German Muñoz (2002) on music and creation in youth cultures; the second part addresses the conceptualization of cyberspace by Pierre Lévy (2007), to try to visualize what perspectives are open to youth cultures from the widespread interconnectivity of XXI century. Finally, a number of implications that has for the pedagogical work in the areas of reading and writing to recognize the participation of students in various youth cultures.

Keywords: Youth cultures, cyberspace, written culture, education.

Las culturas juveniles forman parte de los fenómenos socioculturales más relevantes de nuestro tiempo. Surgidas en Inglaterra y Estados Unidos durante el periodo posterior a la Segunda Guerra Mundial (finales de la década del 50, inicios de la década del 60), han estado ligadas al desarrollo de diversos géneros musicales, a la moda y al surgimiento de nuevos estilos de vida que poco a poco se han ido extendiendo alrededor del mundo. En las primeras reflexiones teóricas (referencias) fue usual asociarlas e identificarlas como un hecho eminentemente urbano, asociadas a formas de resistencia (frente al mundo adulto, a la sociedad industrializada y a las ciudades construidas de asfalto) y trasgresión; y búsqueda de nuevos modos de expresión, al margen de la institucionalidad y la normatividad social.

El punk, el hardcore, el heavy metal, el skin head y el hip hop como expresiones estéticas (musicales, dancísticas, gráficas) de algunas culturas juveniles urbanas -además de otras variantes surgidas como producto de un proceso de hibridación e innovación permanente- han constituido lugares de convergencia para jóvenes que, en muchos casos, se encuentran en situación de precariedad, están frágilmente articulados al sistema escolar, cuentan con limitado capital social y están excluidos de los modos y sistemas convencionales de acción y movilización política, amén de experimentar una sensible incertidumbre acerca del futuro y las posibilidades de encontrar un lugar -su lugar- en la sociedad.

Colombia no ha sido la excepción. A lo largo y ancho de nuestro país, en ciudades grandes y pequeñas, grupos de jóvenes recrean permanentemente desde su cotidianidad local las expresiones de las culturas juveniles que han servido de matriz para creación infinita de variantes acuñadas en el contexto nacional. La música, el baile, el grafiti y los fanzines son algunos de los modos como expresan su visión de mundo, cargada de ambivalencias y contradicciones, pero que permite - desde sus universos de sentidohacer una lectura de nuestra sociedad actual. 
La educación - escenario donde convergen niños y jóvenes que se relacionan directa o indirectamente con las culturas juveniles- no puede estar al margen de estos procesos. En primer lugar, porque las lógicas desde las que opera la cultura escolar entran en tensión con las dinámicas de las culturas juveniles (lo que más adelante desarrollaré como sus móviles y valores) y ello nos obliga a entender qué es lo que allí está sucediendo. En segundo lugar, porque pese a que en la situación actual de Colombia la educación no garantiza a nuestros jóvenes las condiciones mínimas para una existencia digna, no podemos renunciar al compromiso de contribuir a resolver la inequidad que prima en nuestra sociedad. Mientras los jóvenes asistan a las aulas, nuestro compromiso debe permanecer vigente, para que no desistan de hacerlo.

El presente texto (que cabalga entre la reseña y el ensayo) constituye una oportunidad para profundizar en el conocimiento sobre las culturas juveniles, pensar las implicaciones que tiene para ellas el acceso al ciberespacio en el siglo XXI y reflexionar sobre las posturas que debemos asumir desde la institución escolar frente a la presencia de los protagonistas de las culturas juveniles en el ámbito educativo.

En la primera parte, realizo una caracterización de las culturas juveniles a partir de la investigación realizada por Marta Marín y Germán Muñoz (2002) sobre música y creación en las culturas juveniles; en la segunda parte abordo algunos elementos de la conceptualización del ciberespacio realizada por Pierre Lévy para intentar visualizar qué perspectivas se abren para las culturas juveniles a partir de la interconectividad generalizada del siglo XXI. Por último, me refiero a las implicaciones que tiene para el trabajo pedagógico en las áreas de lectura y escritura reconocer la participación de los estudiantes en distintas culturas juveniles.

\section{LAS CULTURAS JUVENILES}

En Secretos de Mutantes (Marín \& Muñoz, 2002), se abordan principalmente el punk, el hardcore, el heavy metal, el skin head y el hip hop, culturas juveniles que se originaron en países distintos al nuestro pero que han encontrado un lugar en ciudades como Bogotá, Medellín, Cali, Pereira, entre muchas otras. Entrelazando la vivacidad de los testimonios juveniles, las letras de canciones representativas, los relatos y las elaboraciones conceptuales, los investigadores nos convierten en testigos indirectos de la manera como se ha ido tejiendo la historia de las culturas juveniles hasta llegar a lo que son a principios del presente siglo.

1. ¿Qué son las culturas juveniles?

Para Marín y Muñoz (2002), no cualquier grupo de jóvenes constituye una cultura juvenil:

(...) desde la dimensión de la creación (entiéndase así la estética), (...) [las culturas juveniles constituyen] múltiples y diversos agenciamientos colectivos de nuestra época, de alta complejidad y dinámica, atravesados por una permanente búsqueda en los dominios de lo ético, lo político, lo artístico, y la producción de conocimiento desde la experiencia. (Marin y Muñoz, 2002, p. 9) 
A partir de lo expuesto por los autores, propongo distinguir tres niveles para caracterizar las culturas juveniles (en adelante CJ): los móviles o motores que las generan, los valores que las aglutinan y los rasgos comunes que tienen entre ellas, derivados de la relación recíproca entre móviles y valores. Valga aclarar que con ello no pretendo desconocer las diferencias entre unas y otras culturas, o entre las distintas derivaciones de una misma cultura.

\section{Los móviles}

Por móviles o motores entiendo aquello que impulsa el nacimiento o la transformación de una cultura juvenil, así como el surgimiento de nuevas derivaciones al interior de una misma cultura. A partir de lo encontrado por Marín \& Muñoz (2002) en su investigación, identifico cuatro móviles:

a) La creación de sí mismo o la construcción de subjetividad (autocreación): consiste en el ejercicio o la práctica de sí mismo, tanto en lo individual como en lo colectivo. Implica la definición pero también la transformación, es decir, la presencia de movimientos, oscilaciones y mutaciones que son inherentes a la producción de la subjetividad. La dimensión creativa del propio sujeto va de lo individual a lo colectivo y viceversa. Tanto la(s) cultura(s) como el(los) individuo(s) se recrean y reconstruyen recíproca y permanentemente.

b) El impulso creativo que conduce a producir alternativas distintas, a romper muros (incluso aquellos que la propia CJ construye alrededor de sus actores) y a construir algo nuevo.

c) La decisión de hacerlo todo por sí mismo (en tanto ejercicio de autonomía) como un motor que ayuda a una cultura a regenerarse cuando ha llegado a un punto muerto.

d) El deseo de cambio, que lleva al integrante de una CJ a encontrar 'lo que es' y 'lo que le gusta'.

e) La búsqueda personal como móvil para la adhesión a una CJ o para marginarse de ella.

f) La búsqueda de la diferenciación que conduce a la multiplicidad de expresiones y a la diversificación de las culturas.

g) El deseo de actuar (de componer, de cantar, de tocar, de bailar, de conocer ...)

h) La provocación y el desafío.

\section{Los valores}

Paralelamente a los motores que impulsan el nacimiento y la transformación de las CJ, se encuentran una serie de valores que comparten los actores reunidos en torno a una cultura. Dichos valores (podría decirse también ideales o principios) se configuran como el horizonte hacia el cual están dirigidas sus acciones. 
a) La individualidad, que prima en las dinámicas de adopción o de abandono de una CJ.

b) La autonomía, que se busca y se construye en el día a día. Las CJ y los sujetos que pertenecen a ellas se autodeterminan. Sus universos de referencia no son coordinados extrínsecamente; su universo ético no corresponde a leyes impuestas desde el exterior. Las CJ se construyen en oposición a las determinaciones externas.

c) El cambio, no como un movimiento que conlleva a un estado superior (es decir, no como evolución), sino como una dinámica de devenir (siguiendo a Deleuze \& Guattari, 1993, citado por Marín \& Muñoz, 2002, p. 274). El cambio puede quedarse sólo en lo físico, pero intenta ser también interior (“del alma”). La mutación que se deriva del cambio y es, por lo tanto, una experiencia corporal y de trascendencia.

En otro sentido, el cambio personal está articulado a la transformación social, como sucede en el Hardcore, en el cual el "cambio radical" significa "rompimiento de normas, jerarquías y estructuras sociales pero, también, un intento diario de evitar que la vida se anquilose" (Marín \& Muñoz, 2002, p. 275). En el caso del Hip Hop, el cambio tiende al mejoramiento y al progreso; consiste en una transformación que debe pasar por las condiciones de vida individuales y de la comunidad. Para los integrantes de esta cultura, la transformación se logra a través de propuestas.

Las CJ tienen dentro de sí el germen del cambio. Por eso sus miembros pueden abandonar una cultura si sienten que ese deseo de cambio es coartado por la pertenencia misma a ella (declaración de un ex punk, citada por Marín \& Muñoz, 2002, p. 281).

d) La diferencia, que juega un papel muy importante al momento de distinguir entre una CJ y las demás.

e) La capacidad de resistencia, que significa chocar contra lo establecido, hacerlo estremecer, fastidiarlo hasta el límite.

Los móviles y los valores de las culturas juveniles no son independientes entre sí, pero no existe entre ellos una relación de causa-efecto. Más bien, forman parte de una compleja red de relaciones cuyo resultado visible -según lo interpreto a partir de la investigación de Marín \& Muñoz- es un conjunto de rasgos que se mencionan a continuación. Rasgos que en el libro cobran vida a través de los relatos orales de los jóvenes, las letras de las canciones, las crónicas escritas por quienes han transitado por las culturas juveniles. Lamentablemente, presentadas aquí parecen como una melodía "muda", un objeto sin textura y sin olor, una música sin ritmo. Asumo el riesgo, en aras de presentar una caracterización que se aproxime a lo que son -en acción- las CJ. 


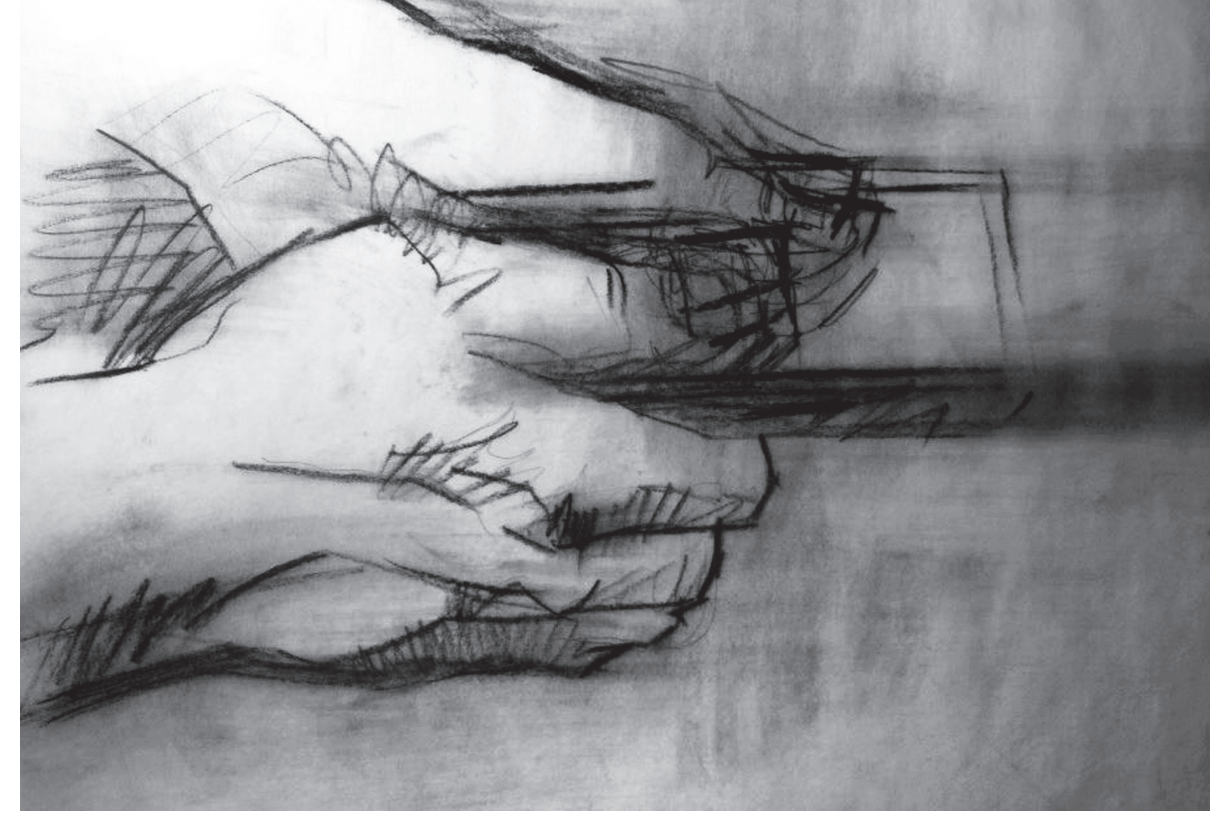

\section{Algunos rasgos que comparten las culturas juveniles}

- La creación al interior de las CJ se produce en el plano underground, al margen de las presiones del mercado y de las decisiones institucionales.

- El mundo de las culturas juveniles -atravesado fundamentalmente por la práctica musicalestá en constante expansión y transformación. Las culturas juveniles organizadas alrededor de la música tienen multiplicidad de manifestaciones. Existe una correspondencia entre cantidad y variedad de géneros musicales y de estilos de vida.

- Las CJ están hechas de paradojas, ambigüedades y ambivalencias. Las CJ son polivalentes:

En su trabajo creativo [las CJ] han producido saberes, formas de vida, cosmovisiones en las cuales hay indudables aportes a renovadas valoraciones de la vida social. Pero éstas coexisten con microfascismos, radicalismos y muchos otros ismos que se incuban en sus propias experiencias. Las culturas juveniles no coinciden estrictamente con instituciones políticas; son mucho más que eso, a veces algo indeterminado, difuso y ambivalente, sin norte ni orden institucional. (Marín \& Muñoz, 2002, p. 19)

- Ese carácter paradójico y ambivalente es quizás una manifestación de lo plural y diverso de toda cultura. Por eso no se habla de cultura juvenil - en singular- sino de culturas en plural. - La mutación es una fase del impulso creativo presente en las CJ. Si el cambio es un ideal de las CJ, la mutación es su manifestación. La mutación y la renovación constituyen constantes en las CJ. Es lo que las mantiene vivas.

- La pertenencia a un grupo no es un acto incondicional; no implica la suspensión o la anulación de los cambios individuales; no significa la renuncia a la búsqueda personal.

- El tránsito por diferentes CJ es una posibilidad siempre abierta, pues al interior de las CJ existen contradicciones, fundamentalismos y tensiones entre autonomía y sujeción, propias de toda construcción de la subjetividad. En dicho tránsito, el joven abandona un cierto tipo de subjetividad construido o promovido en una CJ para emigrar a otra "o hacia coordenadas, encuentros y territorios existenciales nuevos” (Marín \& Muñoz, 2002, p. 279). 
- La tensión que se produce entre el sentido de pertenencia a un lugar y las ansias de libertad forma parte de un movimiento "pendular", de un vaivén que no es sincrónico ni regular.

- La hibridación que está en la base de las CJ se configura a partir del tránsito por atmósferas diferentes pero permeables entre sí (Marín \& Muñoz, 2002, p. 283).

- Las CJ se expanden y se diversifican.

- La heterogeneidad que caracteriza las CJ se produce por confluencia de elementos numerosos y diversos- en la construcción de subjetividades colectivas. Es el resultado de la heterogénesis de toda cultura juvenil y de la permeabilidad entre culturas.

- En las CJ están ausentes las jerarquías. Toda jerarquía contradice los móviles y los valores de las culturas juveniles ${ }^{2}$.

- Las CJ tienen una relación conflictiva con la sociedad y sus instituciones. No obstante, hay un movimiento fluctuante entre la resistencia de la CJ y la integración de ésta al sistema (integración que a veces resulta inevitable). Esto se debe, en parte, a que el mercado o las instituciones se encargan de absorber las manifestaciones de resistencia, para beneficio propio o para frenar su poder contestatario. El germen de la mutación, la búsqueda de individualidad y la autonomía, son las armas con las que las CJ intentan conjurar esta tendencia.

- Las CJ se niegan a ser etiquetadas, formalizadas e institucionalizadas.

\title{
2. Develando los secretos mutantes: perspectiva teórica y metodológica
}

\author{
Busqué la música... \\ y me encontré con la palabra, con la poesía, con la historia... \\ Con las historias (GCB)
}

Me parece importante en este punto, resaltar algunos planteamientos que ponen en evidencia la perspectiva teórica y metodológica asumida por los investigadores Marta Marín y Germán Muñoz frente al tema de las culturas juveniles. En algunos casos, el enunciado que sintetiza el planteamiento está acompañado de una cita textual que puntualiza la postura adoptada.

- De los jóvenes como público a los jóvenes como creadores

Los autores consideran a los jóvenes en tanto “agentes y creadores de sus propias culturas". Por ello, se oponen a la postura dada desde los estudios sobre consumo cultural, los cuales se concentran en "el conocimiento de los jóvenes o de las culturas como público, como audiencias, como destinatarios complejos de las también complejas estrategias de mercado" (Marín \& Muñoz, 2002, p. 37).

- Las culturas juveniles desde la dimensión estética: potencia creativa de las culturas juveniles Resaltar la intensa actividad creativa de los jóvenes en sus propias culturas significa privilegiar en el análisis la dimensión estética, "entendida como una dimensión de creación que durante el siglo XX trascendió los límites del Arte (con mayúscula) para instalarse, entre otros, en los territorios de la existencia y lo vivido” (Marín \& Muñoz, 2002, p. 24). 
Los procesos de creación que los jóvenes llevan a cabo al interior de las CJ se desarrollan en tres ámbitos: en la creación de sí mismos (autoformación) y de nuevas formas de existencia; en la co-creación de sus culturas; y en el desarrollo de diversas modalidades artísticas. En este sentido, los autores destacan que "la potencia creativa propia de las culturas juveniles supera la simple composición de estilos y les confiere un lugar preponderante en la generación, transformación o desarrollo de modos de existencia, marcos de referencia, saberes singulares e incluso nuevas artes" (Marín \& Muñoz, 2002, p. 24).

- En las culturas juveniles la creatividad aplicada a sí mismo y la conformación de subjetividades colectivas no se reduce a la búsqueda de una identidad:

En la medida en que no vemos la identidad como problema, ni como eje único para caracterizar a las culturas juveniles, guardamos distancia. Preferimos asumir el enfoque de la construcción de subjetividades individuales y colectivas, en medio de condiciones difíciles, e incluso adversas, las cuales, siendo determinantes, no inhiben su capacidad creativa (Marín \& Muñoz, 2002, p. 16).

La insistencia en la identidad como algo que debe ser develado, más que inventado, o el encerramiento en una 'adscripción identitaria' impiden pensar la relación que se tiene consigo mismo como un proceso creativo y potencialmente útil para 'resistir, escapar, reorientar la vida o la muerte en contra del poder' (Marín \& Muñoz, 2002, p. 57. Las comillas simples indican la cita de Deleuze, 1995, p. 159).

Los procesos de producción de subjetividades que se realizan en las CJ no se pueden reducir a "un juego de identificaciones y diferenciaciones, con lo cual, según los autores, se invisibilizan "los movimientos, las oscilaciones, las mutaciones inherentes a la producción de subjetividad” (Marín \& Muñoz, 2002, p. 44).

- Los autores no comparten aquellas aproximaciones a las CJ que pretenden sustancializarlas, como resultado de aplicar una lógica binaria de identidades y oposiciones: "El uso de esta lógica binaria en el conocimiento sobre lo juvenil sustancializa las formas de ser joven creadas por las culturas: ser alternativo o ser punk se convierten en sustancias, idénticas a sí mismas, que establecen con ellas mismas y con otras sustancias relaciones también idénticas" (Marín \& Muñoz, 2002, p. 240).

La tendencia a la sustancialización (expresada en el uso de ciertas etiquetas) tiene serias implicaciones, si se tiene en cuenta que "las posibilidades de autogestión, de búsqueda de nuevas formas de existencia y de alternativas frente a eventuales abusos por parte de los poderosos están determinadas en gran parte por el saber disponible sobre las culturas" (Marín \& Muñoz, 2002, p. 240). No por nada, las CJ se resisten a la etiquetación como forma de expresión de esa sustancialización. 
- Marín \& Muñoz (2002) también cuestionan lo que denominan la hiperlocalización del sujeto a partir de la cual el participante de una cultura juvenil se ubica de acuerdo con categorías como género, edad, clase social, tendencia política, etnia, estado de salud, fármacos usados, capacidad laboral y lugar de origen (Marín \& Muñoz, 2002, p. 241). Paradójicamente, la hiperlocalización - pese a considerar elementos diversos para la caracterización de las culturas y sus miembrosconduce a una operación de jerarquización que enfatiza una categoría, en detrimento de las demás. Adicionalmente, la categoría privilegiada es asumida como causa o matriz en la generación de las culturas. Distanciándose de esta perspectiva, los autores plantean que

Más allá de la lógica de identidades y oposiciones, más allá de la sustancialización de las formas de ser joven, más allá de la hiperlocalización del sujeto y de la tiranía del sentido, hay otros modos de establecer conexiones, hay acontecimientos definitivos que suceden en otra escala y que pasan desapercibidos (...) Deberíamos comprender que no todo debe tener sentido, o un sentido, o un sentido permanente y estable. (Marín \& Muñoz, 2002, p. 244)

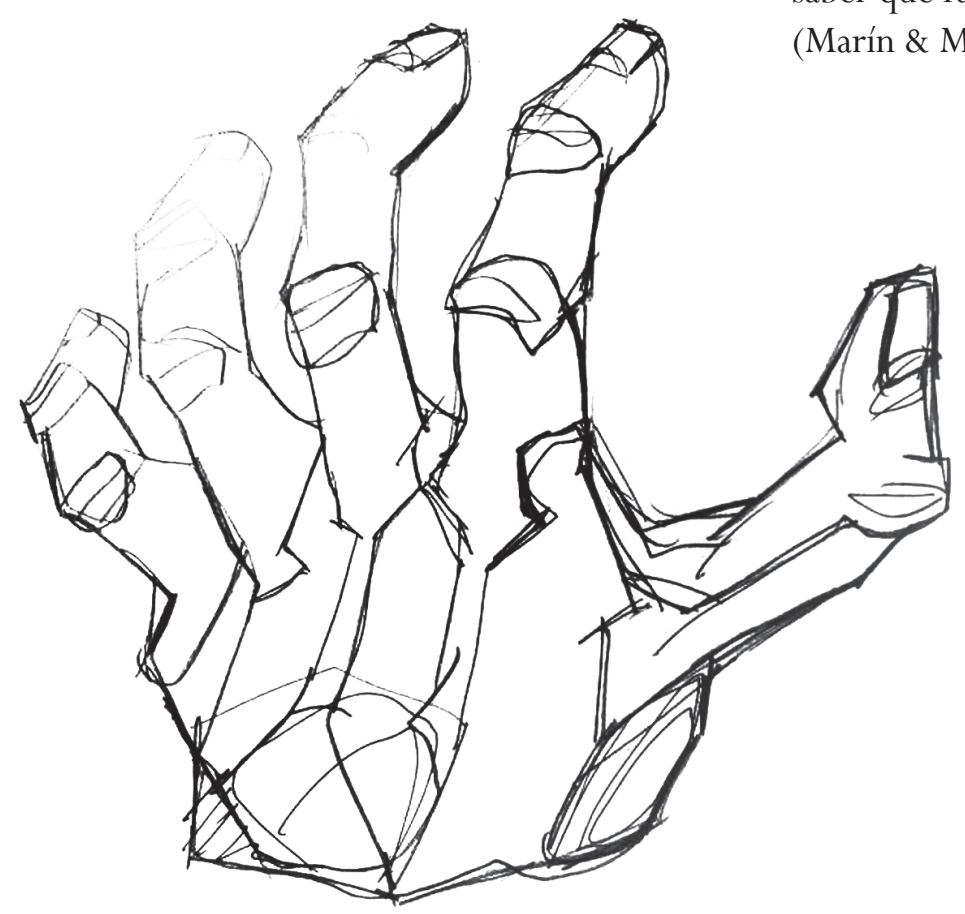

- Pretender comprender, experimentar, conocer a cabalidad y definir de una vez y para siempre las culturas juveniles no solo es inviable, sino que también resulta inconveniente, porque

Las culturas crecen ante nuestros ojos, se reconfiguran y nos obligan a establecer conexiones diferentes cada vez que consultamos una de las muchas versiones de su historia, cuando cae en nuestras manos una nueva canción, cuando un movimiento corporal tiene 'la clave de todo', cuando escuchamos una frase lanzada por uno de los jóvenes participantes o cuando nos asalta una sensación que conecta muchos cabos sueltos. (Marín \& Muñoz, 2002, p. 61)

- Es muy difícil trazar recorridos lineales en las historias de las culturas juveniles. Sus historias se arman como un rompecabezas cuyas piezas no siempre encajan de la misma manera:

Hay también múltiples puntos de vista, imprecisiones temporales, hechos repentinos e ilógicos, y siempre aparecen otras posibilidades de armar la historia gracias a la nueva información. Esto hace dudar de las historias oficiales; incluso lleva a pensar en la imposibilidad de saber qué fue lo que realmente ocurrió”. (Marín \& Muñoz, 2002, p. 160) 
- Los enfoques unívocos y la mono-causalidad resultan precarios para comprender la manera en que "las líneas de sentido se desenvuelven y desarrollan en la CJ, especialmente cuando la música ronda las cercanías" (Marín \& Muñoz, 2002, p. 89).

- Existen matices dentro de las culturas juveniles; sus fronteras se renuevan contantemente; la aceptación o rechazo de ciertos comportamientos y actitudes es cambiante. En ese sentido, un estudio juicioso de las CJ no debe ocuparse de la enumeración exhaustiva de las características de cada una, "pues lo que hay en realidad son muy diversos grados de radicalismo y de formas de adopción, reelaboración y recreación [de las culturas juveniles]" (Marín \& Muñoz, 2002, p. 129).

- Reconocer la heterogeneidad de las culturas conlleva a renunciar a plantear generalizaciones: “Es claro que no se trata de preguntarse 'qué es el joven', ni de buscar esencias o definir tipologías. Se trata de pensar subjetividades heterogenéticas y de darnos cuenta, en primera instancia, de lo poco que sabemos acerca de este proceso creativo" (Marín \& Muñoz, 2002, p. 53).

- No es adecuado abordar el tema de las culturas juveniles desde una óptica que las oponga a lo autóctono y vea en ellas el peligro de la desaparición de lo local.

(...) los motores de creación de las culturas -el "estilo propio" del hip hop y el "hazlo tú mismo" del punk y sus ramificaciones- desafían a quienes piensan que las CJ promueven la pérdida de 'lo autóctono' entre los jóvenes de los países latinoamericanos, africanos y asiáticos. Estas dinámicas sugieren que una formulación adecuada de las preguntas ya no puede partir de la simplista dicotomía propio/ajeno y que conviene buscar otras maneras de entender el complejo fenómeno" (Marín \& Muñoz, 2002, p. 144).

- Las CJ están hechas de múltiples temporalidades. Así por ejemplo, en los modos de subjetivación creados por el punk existen temporalidades propias. Una de las maneras “como los punks llenan el tiempo, lo viven y lo actúan" es el "no futuro, vive el presente" (Marín \& Muñoz, 2002, p. 176).

- Los símbolos de las culturas juveniles tienen un carácter polisémico (esto es particularmente notorio en el caso de la cultura punk). Al ponerse en duda el principio del significado mismo, la atención debe centrarse, entonces, en el proceso de construcción del significado, más que en el producto final.

Finalmente, en lo que respecta a la metodología de la investigación de Marín \& Muñoz (2002), es importante destacar que el análisis realizado por los autores parte de las visiones de mundo que tienen los actores de las culturas juveniles. Más que una observación externa, distanciada, aséptica y pretendidamente neutral, los investigadores intentan ver a las culturas desde la mirada de los jóvenes que participan en ellas. Y para ello, es indispensable darles la palabra: la palabra oral, la palabra escrita, la palabra cantada. 
Cuando me aproximé por primera vez al libro Secretos de Mutantes: música y creación en las culturas juveniles, lo hice con la mirada de alguien con conocimientos sobre música. La verdad, me encontré con un mundo totalmente desconocido, en el que la música no es fundamentalmente la conjugación de melodía, ritmo y armonía, sino un conjunto de complejas vivencias que se expresan con palabras alojadas en la música. Estridente, sí; poco atractiva para algunos (por lo menos para mí, debo confesarlo); pero, sin lugar a dudas, llena de vida.

Las siguientes palabras resumen la experiencia de leer este libro en el cual se explora el complejo mundo de las culturas juveniles organizadas alrededor de la música: Busqué la música... y me encontré con la palabra, con la poesía, con la historia ... Con las historias.

\section{LAS CULTURAS JUVENILES Y SUS POSIBILIDADES EN EL CIBERESPACIO}

No es posible afirmar, sin un trabajo previo de investigación, si existe algo llamado las ciberculturas juveniles. Lo que sí sabemos es que las culturas juveniles desde hace varias décadas están haciendo presencia en el ciberespacio.

En esta sección me propongo abordar las posibilidades que las CJ pueden encontrar en el ciberespacio para desarrollar sus dinámicas. De qué modo las características del ciberespacio permiten que los motores y los valores presentes en las CJ se desplieguen en el permanente fluir, para la diversificación y multiplicación de estas culturas. No se trata, por supuesto, de hacer afirmaciones contundentes sino de insinuar algunas reflexiones o pistas que eventualmente podrían ser retomadas en futuros trabajos de investigación.

A partir de los planteamientos de Pierre Lévy en el libro titulado Cibercultura: La cultura de la Sociedad Digital (2007), presento una definición del ciberespacio, de acuerdo con los valores que encarna y los rasgos más significativos que lo caracterizan ${ }^{3}$. Retomaré sólo aquellos planteamientos del autor que considero pertinentes porque se conectan de algún modo con las características de las CJ y por lo tanto pueden representar desarrollos potenciales para éstas últimas.

\section{El ciberespacio}

Para Pierre Lévy (2007), la técnica no es un factor determinante dentro de una sociedad, sino que condiciona, es decir, abre ciertas posibilidades y opciones culturales o sociales que no se hubieran podido considerar en su ausencia. No todas las posibilidades abiertas por el ciberespacio son escogidas por todos, ni se integran de la misma manera a las realidades sociales y culturales de las comunidades de usuarios (Levy, 2007, p. 10).

Podríamos preguntarnos, entonces, ¿qué opciones se abren para las CJ en el ciberespacio? ¿De qué manera las distintas culturas juveniles acogen las posibilidades abiertas por él? O, por el contrario, podrían algunas de ellas -en virtud de su autonomía- decidir marginarse de los desarrollos propios del ciberespacio? 
El ciberespacio es, desde la perspectiva de Levy, espacio de comunicación, canal de información ligado a la digitalización y soporte de memoria. La siguiente cita enuncia los rasgos característicos del ciberespacio y de la cultura que le es propia (la cibercultura):

Defino el 'ciberespacio' como el espacio de comunicación abierto por la interconexión mundial de los ordenadores y de las memorias informáticas. Esta definición incluye el conjunto de sistemas de comunicación electrónicos (comprendiendo el conjunto de las redes hertzianas y telefónicas clásicas) en la medida en que transportan informaciones provenientes de fuentes digitales o destinadas a la digitalización. Insisto sobre la codificación digital pues condiciona el carácter plástico, fluido, finamente calculable y tratable en tiempo real, hipertextual, interactivo $y$, para decirlo todo, virtual, de la información que es, me parece, la marca distintiva del ciberespacio. Este nuevo medio tiene por vocación poner en sinergia y en interfaz todos los dispositivos de creación de información, de grabación, de comunicación y de simulación. La perspectiva de la digitalización general de las informaciones y de los mensajes hará probablemente del ciberespacio el principal canal de comunicación y el primer soporte de memoria de la humanidad a lo largo del siglo XXI. (Lévy, 2007, p.71)

Los principales modos de comunicación y de interacción que permite el ciberespacio son, según el autor: el acceso a distancia a los diversos recursos de un ordenador (Lévy, 2007, p. 72); las funciones de mensajería (correo electrónico); las conferencias electrónicas (dispositivo "que permite a grupos de personas discutir juntos sobre temas particulares") (Lévy, 2007, p.77); la comunicación a través de un mundo virtual compartido [“... mantener una relación sensorio motriz con el contenido de una memoria informática”, en función o en el contexto de la interacción con otros individuos en un dispositivo del tipo todos-con todos" (Lévy, 2007, p.78)].

El ciberespacio inaugura dos dispositivos informacionales ${ }^{4}$ : el mundo virtual y la información en flujo ${ }^{5}$. En lo que respecta a los dispositivos comunicacionales $^{6}$, "el ciberespacio establece un dispositivo comunicacional original [todos-todos] que permite a comunidades constituir progresivamente y de manera cooperativa un contexto común", desarrollar una comunicación ininterrumpida $\mathrm{y}$ como consecuencia de ello generar una memoria colectiva "que emerge de la comunicación entre los participantes” (Lévy, 2007, p. 49).

\section{Rasgos característicos del ciberespacio}

Los rasgos que caracterizan el ciberespacio son: interconectividad (o conectividad global); accesibilidad a distancia, que conlleva a la universalidad; interacción (el ciberespacio es dispositivo de comunicación interactivo y comunitario); desterritorialización; digitalización; virtualización; procesos de simulación; velocidad en los procesos y en los cambios que genera el ciberespacio; hipertextualización; posibilidad de configuración de una memoria colectiva que resulta de la comunicación ininterrumpida, propia del dispositivo comunicacional todos-todos; sinergia; multimedialidad; desarrollo de comunidades virtuales; tendencia a la universalidad - expresada en la ausencia de un orden predeterminado y de un centro-, resultado de la suma de la interconectividad y la digitalización; inteligencia colectiva, finalidad última y perspectiva espiritual de la cibercultura. 
En cuanto a los valores que encarna la cibercultura, podemos mencionar: La información (lo que contiene y trasporta el ciberespacio; aquello que producen y a lo que acceden los usuarios del ciberespacio); la autonomía; la interconexión generalizada como utopía, que emerge como nueva forma de lo universal; la inteligencia colectiva (uno de los principios y motores de la cibercultura); lo universal sin totalidad, significación última de la red.

\section{De las culturas juveniles en el ciberespacio a las culturas juveniles del ciberespacio}

Con base en lo anterior, encuentro que las características del ciberespacio y las posibilidades de comunicación que inaugura o potencializa pueden estar en consonancia con los móviles y con los valores de las culturas juveniles. Esto, en principio, se puede manifestar de la siguiente manera:

1. Las CJ pueden encontrar en los dispositivos informacionales promovidos por el ciberespacio la posibilidad para fortalecer nexos con los distintos participantes, en una dinámica que no propicie la homogenización, sino que permita acceder en tiempo real a las manifestaciones que se producen en distintos contextos geográficos. Además, el dispositivo comunicacional 'todos -todos' es coherente con la ausencia de jerarquías que caracteriza las CJ.

2. Tanto las CJ, como el ciberespacio, carecen de una esencia estable, pues se transforman constantemente. Esto podría significar que algunos actores puedan sentirse en el ciberespacio como "pez en el agua" a la hora de proponer, crear, resignificar o transformar productos derivados de las culturas juveniles. El ciberespacio y las posibilidades comunicativas que de él se derivan serían como una suerte de instrumento maleable, que armonizaría con las tendencias a la mutación y a la diversificación de las culturas.

3. La interconexión puede potenciar el proceso de expansión, diversificación y fusión de las CJ; el desarrollo de proyectos conjuntos; la dinámica tendiente a la diferenciación y búsqueda permanente (individual y colectiva), que se facilita si hay mayores posibilidades de comunicación con otros participantes de las culturas en distintos lugares del mundo.

4. El ciberespacio permite la circulación de textos que no han pasado por el filtro de editores, redactores o comités científicos. Esto significa, por un lado, la posibilidad de dar a conocer nuevas ideas y experiencias, que tienen todas las personas o grupos sociales, sin contar para ello con el aval de los especialistas reconocidos. 
Por otro lado, los individuos pueden acceder a las "fuentes vivas del saber" y articularse a comunidades virtuales dedicadas al aprendizaje cooperativo, sin necesidad de autorización alguna, al margen de los constreñimientos de las instituciones formales educativas.

Sin lugar a dudas, estas posibilidades encajan con el "hazlo tú mismo" y el "cualquiera puede" de las CJ; proporcionan facilidad para la búsqueda y la experimentación; permiten a los participantes acceder a recursos sin limitaciones de tiempo y espacio, de tal manera que desde sus criterios individuales opten por las alternativas que mejor concuerden con sus intereses y expectativas.

5. La virtualización ${ }^{7}$ representa para las CJ la posibilidad de que sus actores se relacionen sin que para ello deban coincidir geográfica y temporalmente, y a partir de allí, dar y recibir aportes, contribuyendo de este modo a alimentar una memoria común. Por otro lado, aunque no es lo mismo hablar de comunidades virtuales y de culturas juveniles, ambas encuentran en el ciberespacio la posibilidad de desarrollar sus proyectos sin que la distancia física constituya una barrera ${ }^{8}$. Aunque como lo dije antes, no es posible aún plantear la existencia de algo denominado las “ciberculturas" juveniles, creo que si algo nos permitiría hablar de una existencia específicamente ciberespacial de las CJ, es la virtualidad, en sus distintas manifestaciones ${ }^{9}$.

6. La inteligencia colectiva que se potencia con la cibercultura guarda una estrecha relación con la manera colectiva en que se construyen, se transforman, se recrean y diversifican las culturas juveniles.

La inteligencia colectiva es definida por Pierre Lévy (1999) como "la valoración, la utilización óptima y la sinergia de las capacidades, las imaginaciones y las energías intelectuales, sea cual sea su diversidad cualitativa y su ubicación". Lograr ello implica necesariamente "un uso compartido de la memoria, la imaginación y la experiencia, la práctica vulgar del intercambio de conocimientos y la introducción de nuevas formas de organización y coordinación flexibles y en tiempo real" (Lévy, 1999, p. 9).

El desarrollo de los procesos de inteligencia colectiva conlleva al cuestionamiento de diversos poderes; permite una mejor apropiación de los cambios técnicos por parte de los individuos y los grupos; ayuda a contrarrestar los "efectos excluyentes o humanamente destructores" que trae consigo "la aceleración del movimiento tecnosocial" (Lévy, 2007,p. 13). Como puede inferirse al leer los planteamientos de Lévy, todas las ventajas que el autor le atribuye a la inteligencia colectiva son coherentes con los móviles e ideales de las CJ, expuestos en la primera parte de este documento. 
7. Lo universal sin totalidad es, a mi modo de ver, el rasgo del ciberespacio que mayor correspondencia tiene con los móviles y valores de las culturas juveniles.

El carácter universal del ciberespacio está dado por la posibilidad de interconectividad, y digitalización/virtualización. El acceso a la red, sin restricciones, posibilita que los usuarios del ciberespacio aporten -sin censura alguna- a la información que circula en él y se alimenten -sin restricciones- de las contribuciones de los demás.

El tipo de universalidad que posibilita el ciberespacio se diferencia del que fue instaurado por la escritura y del que -tributario de éste último - es implementado actualmente por los medios de comunicación ${ }^{10}$. Para Lévy, lo universal debe entenderse como "una especie de aquí y ahora virtual de la humanidad" (Lévy, 2007, p. 90). Por eso no debe confundirse con 'totalidad', pues la 'totalización' en las formas culturales derivadas de la escritura “opera sobre la identidad de la significación” (un significado único para todos, siempre y en cualquier lugar) (Lévy, 2007, p. 90).

Lo universal sin totalidad, inaugurado por el ciberespacio, es resultado de la interconexión generalizada; no está articulado al cierre semántico exigido por la descontextualización; "no totaliza a través del sentido, sino que reenlaza por el contacto, por la interacción general"; desliga universalidad y totalidad; se experimenta por inmersión y no por la identidad de sentido; permite el "acceso a un goce de lo mundial, a la inteligencia colectiva en acto de la especie"; "nos hace participar más intensamente en la humanidad viva, [pues da lugar a] la multiplicación de las singularidades”; no se entiende como una "dilatación de lo local" ni como "la exportación forzada de los productos de una cultura particular”; expresa la diversidad de lo humano (Lévy, 2007, pp. 92-93).

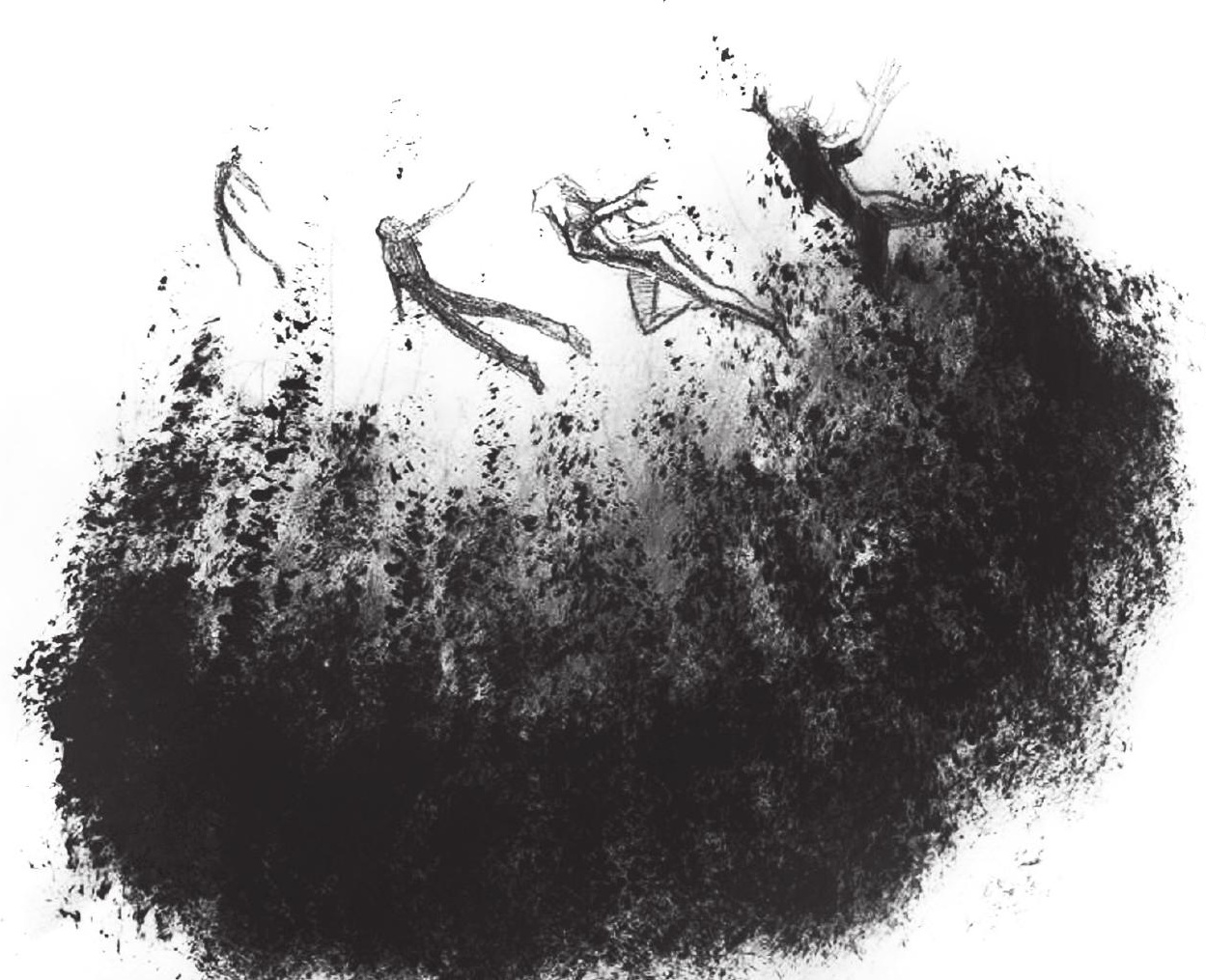


En ese sentido, podríamos afirmar que lo universal sin totalidad forma parte del horizonte en el que inscriben las prácticas de la culturas juveniles y que por lo tanto, el ciberespacio representa la posibilidad de que sus móviles e ideales encuentren formas novedosas de desarrollo. Esto, sin olvidar que son las mismas culturas las que han de ir definiendo los alcances en cuanto al uso del ciberespacio, de tal manera que se puedan estar dando los pasos hacia el nacimiento (quizás ya se está dando, no lo sabemos) de los rasgos particularmente ciberespaciales de las culturas juveniles. ¿Cuál será, entonces, la impronta de las culturas juveniles del ciberespacio? Seguramente en un futuro no muy lejano podremos saberlo...

\section{LECTURAS, ESCRITURAS Y CULTURAS JUVENILES}

Pareciera - a primera vista- que las dinámicas propias de las culturas juveniles y las de la cultura escrita son irreconciliables. Si por un lado las culturas juveniles se construyen en oposición al orden social y a sus instituciones, por el otro, el dominio de la cultura escrita significa la apropiación de un canon normativo requerido para lograr que en ausencia del autor de un texto, su lector pueda captar no sólo lo dicho, sino la manera como el autor quería ser interpretado ${ }^{11}$.

La institución escolar y la cultura que agencia (cultura escolar) es uno de los lugares privilegiados donde se promueve la adscripción de los estudiantes a la cultura escrita ${ }^{12}$. En la mayoría de los casos, esto se hace desconociendo varios hechos, entre ellos: que a partir de sus experiencias en el ámbito familiar y en otros espacios de socialización (ente ellos la participación en las culturas juveniles, el contacto con los medios de comunicación, la utilización de las tecnologías informáticas, etc.), los estudiantes tienen grados y modos distintos de relacionarse con la cultura escrita. Y que en la actualidad, con el auge de las nuevas tecnologías, estamos asistiendo a la emergencia de otros cánones de escritura que no sólo ponen en tensión el canon legítimo, sino que cada vez distancian más las prácticas cotidianas de los estudiantes de los aprendizajes promovidos por la escuela.

\section{Procesos educativos de lectura y escritura: el lugar de las culturas juveniles}

La pregunta de investigación del proyecto de tesis doctoral que desarrollo actualmente se enmarca en el estudio de las formas actuales que adquiere la cultura escrita en el contexto de los usos de las tecnologías informáticas y - a partir de allí- en la posibilidad de proponer la escritura digital como una nueva fase de la cultura escrita.

Leer Secretos Mutantes: música y creación en las culturas juveniles ha significado para mí la posibilidad de conocer otras escrituras con las que los jóvenes tienen una estrecha relación: las letras de las canciones que crean, cantan o escuchan. Se trata, como lo dijeran los autores, de "condensados sensoriales, verdaderos recursos mnemotécnicos, una suerte de álbumes de fotos de la cultura en los que las imágenes tienen movimiento, sonido, hasta olor... y están absoluta, definitivamente cargadas de emoción" (Marín \& Muñoz, 2002, p. 160). 
La lectura del libro y la realización del presente artículo tienen tres antecedentes que considero pertinente mencionar. En primer lugar, la realización de la investigación Lecturas y Escrituras Juveniles: entre el placer, el conformismo y la desobediencia (Carvajal, 2008) $)^{13}$, la cual aborda las prácticas de lectura y escritura de cinco jóvenes universitarios en el contexto de sus prácticas de consumo y producción cultural. La realización de grupos de discusión y entrevistas en profundidad permitió identificar la manera como los estudiantes, en sus trayectos de vida, se constituyeron como sujetos productores y consumidores de bienes simbólicos y construyeron su relación con la lectura y la escritura en espacios de sociabilidad como la escuela, la familia y el barrio. Ninguno de los estudiantes entrevistados pertenecía en ese momento a una cultura juvenil $^{14}$, pero en su calidad de sujetos en condición juvenil ${ }^{15}$ (Muñoz, 2012) comparten algunas de sus expectativas y deseos con los protagonistas de las culturas juveniles. A partir de la realización de la investigación y de la publicación del libro citado, escribí un artículo en el que propuse cinco premisas para el trabajo pedagógico en las áreas de lectura y escritura en la universidad (2010), de lo cual retomaré algunos planteamientos. Además, a partir de esa investigación quedó sembrada la inquietud de explorar más a fondo la relación de los estudiantes con otro tipo de textos verbales provenientes de los medios y las industrias culturales, como las letras de las canciones de su preferencia, las emisoras radiales que escuchaban y los mensajes publicitarios.

En segundo lugar, la propuesta de investigación que presenté para aspirar al Doctorado en Ciencias de la Educación tenía como uno de sus ejes temáticos la oralidades juveniles y su relación con las prácticas de consumo y producción cultural. Dicho eje consideraba una aproximación a productos culturales como las canciones, los mensajes publicitarios, el grafiti y el esténcil. En medio de las dos (de la investigación de maestría y la propuesta inicial para la tesis doctoral) participé en una investigación realizada entre el 2003 y el 2009, en la cual abordamos las relaciones entre cultura escrita, conocimiento y tecnocultura en la Universidad del Valle (Ulloa \& Carvajal, 2006).

Menciono estos antecedentes para señalar que la lectura del libro de Marín \& Muñoz movilizó nuevamente mi interés por seguir conociendo los distintos registros de las lecturas y escrituras juveniles, como un requisito indispensable para orientar y enriquecer el trabajo pedagógico en esta área de formación. Como suele suceder, la idea inicial de un proyecto de investigación se va transfigurando y actualmente las preguntas formuladas en la propuesta inicial relacionadas con la música que cantan y escuchan los jóvenes, fueron desplazadas en el proyecto de tesis doctoral. De todas maneras, es ésta una oportunidad para plantear una serie de inquietudes en las que artículo el tema de las culturas juveniles con algunas de las líneas en las que se mueve mi trabajo docente e investigativo en la Universidad del Valle.

La pregunta de la que parto es la siguiente: ¿cómo actuar desde la institución escolar frente a las manifestaciones de las CJ que franquean los muros de colegios y universidades y se expresan de distintas maneras en las formas de vestir, de inter-actuar, pero también de hablar, escribir y leer de los estudiantes? 
No creo que la solución sea ignorarlos, como tampoco la de posar de "jóvenes" (en una suerte de 'condición juvenil' artificiosa), para ocupar un lugar que no nos corresponde en aras de lograr una mayor cercanía con los estudiantes. Creo, en cambio, que como docentes debemos reconocer al otro (a los otros) como sujetos distintos, autónomos y en construcción. Una construcción en la que la participación en las culturas juveniles juega un papel muy importante (por lo menos para algunos de ellos); una construcción de la que nosotros empezamos a formar parte desde el momento en que el joven accede a la cultura escolar.

A continuación, presento cinco consideraciones relacionadas con un doble reconocimiento: (a) de las culturas juveniles como espacios donde también se construyen relaciones con la cultura escrita; y (b) de los espacios formativos en lectura y escritura como posibles lugares de reconstrucción de un sujeto que la cultura escolar ha pretendido dividir, dejando por fuera lo que riñe con sus lógicas ${ }^{16}$.

1. Las culturas juveniles son espacios de producción y consumo cultural ${ }^{17}$ que no pueden ser ignorados en los procesos formativos de lectura y escritura.

La participación de algunos estudiantes en las diferentes culturas juveniles existentes forma parte de su historia como consumidores y productores de bienes simbólicos. Dicha participación muy probablemente ha significado modos particulares de relacionarse con la lectura y la escritura, bien sea a través de los textos de las canciones que crean e interpretan, la producción o lectura de fanzines, la escritura de crónicas en la red o la participación en foros virtuales que abordan temas cruciales para la cultura juvenil a la que pertenecen. Un tema interesante de investigación podría ser explorar de qué manera esas escrituras y lecturas se nutren de las prácticas producidas en el espacio escolar o si por el contrario riñen con ellas; si las tensiones entre escrituras realizadas en las culturas juveniles y la escritura canónica propiciada en la escuela constituyen un factor inhibidor para leer y escribir, o si la búsqueda de autonomía de los jóvenes los lleva a proponer alternativas de expresión no previstas ("derrumbar muros para construir algo nuevo").

Desde mi punto de vista, la orientación en el campo de la lectura y la escritura (como parte de la cultura escolar) requiere: (a) Reconocer que las prácticas culturales y comunicativas que se desarrollan dentro de las CJ permean el trabajo formal e institucionalizado de la escuela. (b) Indagar sobre los perfiles de producción y consumo cultural de los estudiantes, incluyendo lo relacionado con su participación en las CJ. (c) Asumir que las experiencias de vida, las rutinas de consumo cultural, las expectativas y los deseos de los jóvenes, lejos de convertirse en un obstáculo para el proceso formativo, constituyen un recurso que lo enriquece. 


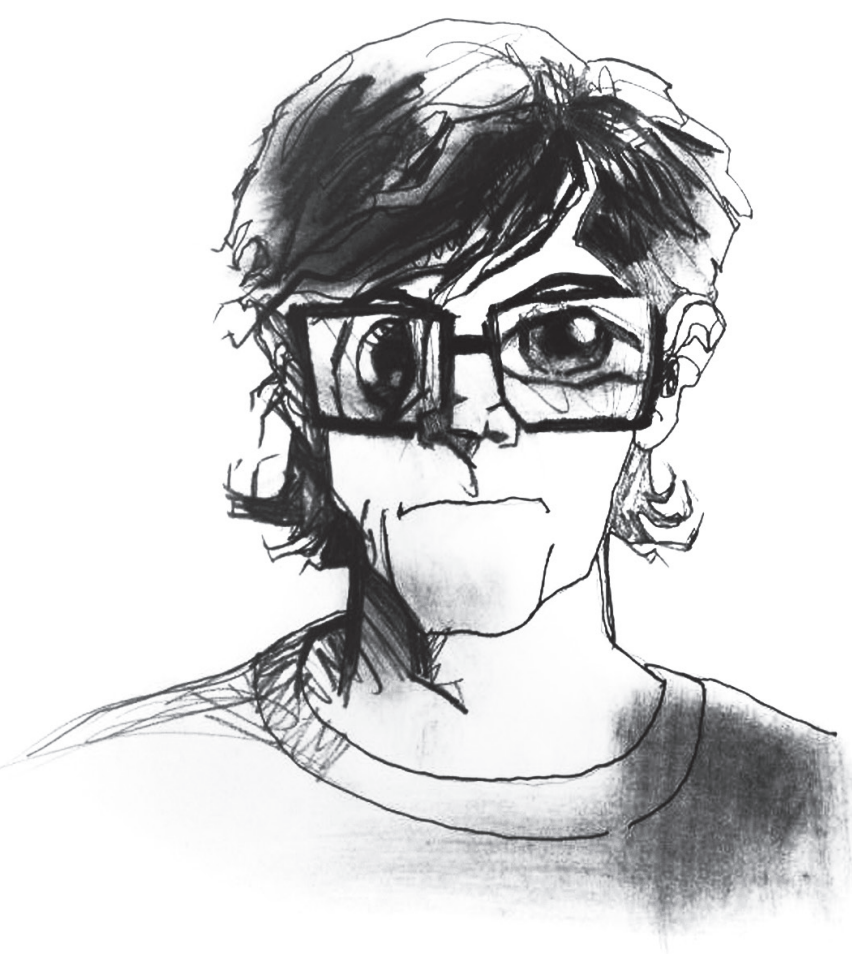

2. Es importante reconocer que las CJ forman parte de las experiencias existenciales de quienes participan en ellas.

En lugar de ignorarlas o proscribirlas, es importante involucrarlas en las dinámicas educativas. No para formalizarlas o institucionalizarlas, sino para que los conocimientos derivados de las CJ puedan ponerse en relación con otros conocimientos promovidos por la escuela, por los medios de comunicación y las tecnologías informáticas. Deberíamos pensar - como parte de nuestro trabajo pedagógico- en integrar todas las experiencias de los jóvenes estudiantes, para mitigar la fragmentación de la que es víctima el sujeto cuando se ignoran ciertas facetas de su existencia. Ello no quiere decir que las CJ dejen de existir, que dejen de tener sus propios espacios y sus propias lógicas. Independientemente de lo que hagamos o dejemos de hacer, las CJ se expandirán y se transformarán a voluntad de quienes participan en ellas, en medio de tensiones que se resuelven siempre de manera tentativa y parcial. Tampoco quiere decir que la cultura escolar renuncie a las funciones que la sociedad (querámoslo o no) le ha designado, entre ellas el agenciamiento de la cultura escrita.

3. La investigación sobre lecturas y escrituras juveniles mostró que en nuestras aulas estamos ante un tipo de escritores y de lectores interesados en la comunicación de emociones, y ello se manifiesta en su gusto o en su aversión hacia determinados tipos de escritura y de lectura.

Se expresa también en la distinción que hacen entre la escritura escolar (obligatoria, institucional, coercitiva) y la escritura libre o autónoma, en cuya base se encuentran formas de sociabilidad que en la mayoría de los casos son subvaloradas e ignoradas por la escuela. Este papel de la escritura como una forma de expresar emociones e inquietudes, afrontar dificultades, imaginar, soñar, añorar o recordar es una de las dimensiones en las que se expresa el vínculo entre escritura y construcción de la subjetividad, y por lo tanto es uno de los puntos a considerar en un trabajo pedagógico. En algunas de las canciones citadas por Marín \& Muñoz (2002) se puede apreciar algo de lo que aquí describo. Muchas de las críticas de los grupos musicales a la sociedad y a sus instituciones, al mercado, a los gobiernos, están cargadas de rabia, de escepticismo o de desesperanza. 
4. Como lo mostró la investigación citada, el lugar de la escritura en la vida de los jóvenes tiene que ver, además, con la incidencia de la escuela, en tanto escenario de ‘publicación' de lo escrito.

Hacer públicos los textos significa poner en circulación al autor como sujeto que se expone en contextos sociales concretos. Leer lo escrito en un aula de clases significa exponerse ante todos, con los riesgos que ello implica. Sin embargo, a diferencia de lo que sucede en las CJ, exponerse a los otros en el aula de clases no es siempre el resultado de una decisión, sino que en la mayoría de los casos es producto de una obligación. Muy distinto sería si la idea de que "cualquiera puede" escribir funcionara como un factor motivador para los estudiantes. Ese puede constituir el inicio de un camino en el que la búsqueda de sí mismo a través de la escritura sea también una oportunidad de aprender, de apropiarse de los recursos que ofrece la cultura escrita para expresar el propio pensamiento.

La escritura se potencia como forma de expresión si se comparte con otros, si se conecta a redes de sociabilidad.Y en esto, las CJ (donde el "hazlo tú mismo" moviliza la creación textual y musical) son un ejemplo que deberíamos aprender. Desde mi perspectiva,

La puesta en común de la producción escrita es la clave para hacer de esta práctica cultural una actividad enriquecedora para nuestros jóvenes. Reconocer la dimensión social pero también subjetiva de escritura, permitiría que ésta ocupe un lugar importante tanto en la aprehensión como en la generación de conocimientos, en la construcción de posturas autónomas ante la realidad, en el fortalecimiento de vínculos sociales que posibiliten el desarrollo personal y aporten para el mejoramiento del mundo que habitamos.Y esto se podrá lograr si el ámbito escolar se piensa como escenario de producción, de re-creación y de transformación, donde tengan cabida las distintas dimensiones existenciales del sujeto, en cuya configuración la escritura - en tanto forma de expresión- juega un rol fundamental. (Carvajal, 2010, p. 214)

No me refiero, por supuesto, a limitar el trabajo pedagógico a la promoción de una escritura libre y espontánea, pues considero que nuestro compromiso como docentes es formar a los estudiantes en el conocimiento de los distintos cánones de la cultura escrita, orientarlos para que se apropien de los conocimientos de las disciplinas científicas, las humanidades y las artes, y lograr que la escritura constituya una forma de comunicación eficaz. Esto es posible si propiciamos un encuentro (o un reencuentro) de los jóvenes con la escritura, si damos cabida a formas de sociabilidad donde tenga sentido el acto de escribir. Pero no como una manera de controlar y medir los aprendizajes escolares sino como un recurso de expresión y una herramienta para la construcción de saberes que se insertan a la vida de los jóvenes y les permiten conocer y transformar el mundo (Carvajal, 2010, p. 215). 
Lo anterior implica "un salto de la escritura como proyecto expresivo a la escritura como proyecto de comunicación”. En la primera, predomina el interés de plasmar las ideas, reflexiones y pensamientos ligados a vivencias personales, sin pensar en el destinatario y sin reconocer la necesidad de que el escrito tenga los referentes que contextualicen los tópicos tratados y cumpla con la normatividad propia de la enunciación escrita. En la segunda, la escritura empieza a considerarse un medio de comunicación (distinto a la oralidad) que tiene parámetros definidos. Y para dar este salto es fundamental que en el proceso de enseñanza, además de diseñar metodologías adecuadas, se cree un ambiente favorable para la comunicación, es decir, para la construcción de redes de intercambio social en las que se enmarquen la producción escrita de los estudiantes (Carvajal, 2010, pp. 215-216).

Reconocer la existencia de la escritura como proyecto expresivo y asumir la importancia de la cultura escrita en el desarrollo cognitivo, psicológico y social de los estudiantes es un paso fundamental para reactivar el interés y el gusto por la escritura. Pero el objetivo del proceso pedagógico va más allá: convertir la escritura en una herramienta del pensamiento (en una mediación cognitiva) y en una forma de comunicación eficaz. Esto último no significa renunciar a la escritura como forma de expresión de la subjetividad, sino, por el contrario, adquirir los conocimientos y las habilidades procedimentales necesarias que permitan a los estudiantes enriquecer su visión del mundo, situarse críticamente frente a él y emplear la escritura como una herramienta fundamental para analizar y construir la realidad (Carvajal, 2010, p. 216).

5. Finalmente, deberíamos permitir a los estudiantes 'ser' en el espacio escolar, en el aula de clases, en las prácticas que promovamos en su interior.

Y ello implica abrir espacios para sus diferentes experiencias de vida. La participación en las culturas juveniles, lejos de significar un obstáculo puede representar para nosotros una lección en la labor pedagógica: ¿será acaso una utopía lograr que nuestros estudiantes encuentren en la escritura y en la lectura herramientas para crearse a sí mismos, una oportunidad para construir o fortalecer la autonomía, una forma de canalizar el impulso creativo que conduce a producir alternativas distintas, una manifestación de su deseo de hacer la cosas por sí mismos, un camino para buscar y marcar diferencias, una herramienta para el cambio, una provocación, un desafío, una manera de actuar en el mundo - entre muchas otras posibles-, un modo 'de vivir sin límites' y de 'experimentar libremente'? 
No creo que los móviles y los ideales de las culturas juveniles estén en contra de la sociedad. Lo que creo es que nuestras sociedades no están preparadas para hacer posible lo que ellos imaginan que debería ser y existir; no dejan espacio para pensar, para decidir, para actuar. Creo que muchos de nuestros jóvenes - entre otras razones, por las precarias condiciones en que viven- no han encontrado el lugar para construirse dentro de la sociedad, que sus talentos permanecen ocultos para el mundo adulto institucionalizado y quizás nunca encuentren el modo de potenciarlos a favor de sus comunidades. Creo que es hora de hacer algo desde donde estemos. La escuela, el colegio, la universidad son lugares desde donde debemos actuar, con lo que consideramos saber hacer y contando con lo que los jóvenes nos puedan enseñar.

Las culturas juveniles viven. La escuela, además de existir, tiene que empezar a latir...

\section{Notas}

${ }^{1}$ Profesora de la Escuela de Comunicación Social de la Universidad del Valle. Comunicadora Social, Licenciada en Música, Magíster en Comunicación y Diseño Cultural. Candidata a doctora en Ciencias de la Educación de Rudecolombia-Universidad Tecnológica de Pereira. Su proyecto de tesis doctoral se titula Cultura escrita en el ciberespacio: ¿nuevos conocimientos, nuevos conceptos, nuevas prácticas?

${ }^{2}$ No creo, de todos modos, que las relaciones de poder estén ausentes al interior de las culturas juveniles, pero en este documento no me propongo argumentar esta apreciación.

${ }^{3}$ Como sucede con las CJ, la identificación de los valores y los rasgos del ciberespacio constituye una elaboración propia a partir de la obra de Pierre Lévy.

${ }^{4}$ La categoría dispositivo informacional se refiere a la estructura del mensaje o al modo en que se relacionan los elementos de información: lineal o en red.

5 "El mundo virtual dispone las informaciones en un espacio continuo - y no en la red- y ello en función de la posición del explorador o de su representante en el mundo (principio de inmersión). (...) La información en flujo designa los datos continuamente cambiantes y dispersados entre memorias y canales interconectados que pueden ser recorridos, filtrados y presentados al cibernauta según sus instrucciones gracias a agentes de programas, sistemas de cartografía dinámica de datos u otras ayudas a la navegación" (Lévy, 2007, p. 48).

${ }^{6}$ Con la categoría dispositivo comunicacional Lévy alude al tipo de relación que se establece entre los participantes de la comunicación: Por ejemplo, en el dispositivo uno-todos "un centro emisor envía sus mensajes a un gran número de receptores pasivos y dispersos", como sucede en la prensa, la radio y la televisión. En el dispositivo uno-uno se "organizan relaciones recíprocas entre interlocutores pero solamente según contactos de individuo a individuo o de punto a punto". Es el caso del correo y del teléfono (Lévy, 2007, pp. 47 a 49). 
${ }^{7}$ De las tres acepciones que tiene la palabra virtual (el sentido filosófico; el sentido técnico, ligado a la informática; y el sentido corriente, que opone lo virtual a lo real), Pierre Lévy adopta el sentido filosófico, por cuanto es el que le permitirá plantear que lo virtual es una dimensión -muy importante, además- de la realidad. Según la acepción filosófica, "es virtual lo que no existe más que en potencia y no en acto, el campo de fuerzas y problemas que tienden a resolverse en una actualización. Lo virtual está más allá de la concreción efectiva o formal (el árbol está virtualmente presente en la semilla)". Teniendo en cuenta lo anterior, desde el rigor de la filosofía, "lo virtual no se opone a lo real sino a lo actual: virtualidad y actualidad son solamente dos modos diferentes de la realidad. Si en la esencia del grano está producir un árbol, la virtualidad del árbol es real (sin ser aún actual) “(...) aunque no se le pueda fijar en ninguna coordenada espaciotemporal, lo virtual es sin embargo real” (Lévy, 2007, p. 33).

${ }^{8}$ La distinción entre comunidades virtuales y culturas juveniles requiere de un trabajo de indagación que supera los alcances del presente documento. No obstante, me atrevo a insinuar que si bien una cultura juvenil puede constituirse como una comunidad -lugar de confluencia, desarrollo de propósitos comunes, cohesión en torno a ciertos valores, sentido de pertenencia, entre otros aspectos- no toda comunidad virtual constituye una cultura juvenil, si partimos de la conceptualización hecha por Marín y Muñoz (2002).

${ }^{9}$ Según lo planteado por Lévy (2002), la cibercultura está ligada a lo virtual de manera directa e indirecta. "Directamente la digitalización de la información puede ser asimilada a una virtualización", pues los códigos informáticos, aunque son invisibles se pueden transferir de un nudo a otro de la red y son "casi independientes de las coordenadas espaciotemporales determinadas. En el seno de las redes digitales, la información está evidentemente físicamente situada en alguna parte, en un soporte dado, pero está también virtualmente presente en cada punto de la red donde se la pedirá". Además, "la información digital (traducida en dígitos 0 y 1 ) pude ser también calificada de virtual en la medida en que es inaccesible como tal al ser humano. No se puede conocer directamente más que su actualización por medio de un modo de exposición u otro" (Lévy, 2007, p. 34). "Indirectamente, el desarrollo de las redes digitales interactivas favorece otros movimientos de digitalización distintos de aquellos de la información propiamente dicha. Así, la comunicación prosigue con lo digital un movimiento de virtualización iniciado desde hace tiempo por medio de técnicas más antiguas tales como la escritura, como la grabación del sonido y de la imagen, la radio, la televisión y el teléfono. El ciberespacio anima un estilo de relación casi independiente de los lugares geográficos (telecomunicación, telepresencia) y de la coincidencia de los tiempos (comunicación asincrónica). Sólo las particularidades técnicas del ciberespacio permiten a los miembros de un grupo humano (que puede ser tan numeroso como se crea) coordinarse, cooperar, alimentar y consultar una memoria común, y esto casi en tiempo real a pesar de la distribución geográfica y las diferencias horarias" (p. 35).

${ }^{10}$ El tipo de universalidad de los medios se basa en la unificación del sentido (cierre semántico) y hace que se identifiquen como uno solo universal y totalidad. A esta forma de lo universal corresponde la definición del sentido de lo escrito que - por fuera del contexto de la enunciación (que sí posibilitaba la oralidad)-, debía ser precisado por el autor y descifrado por el lector, en correspondencia con unos modelos legitimados socialmente.

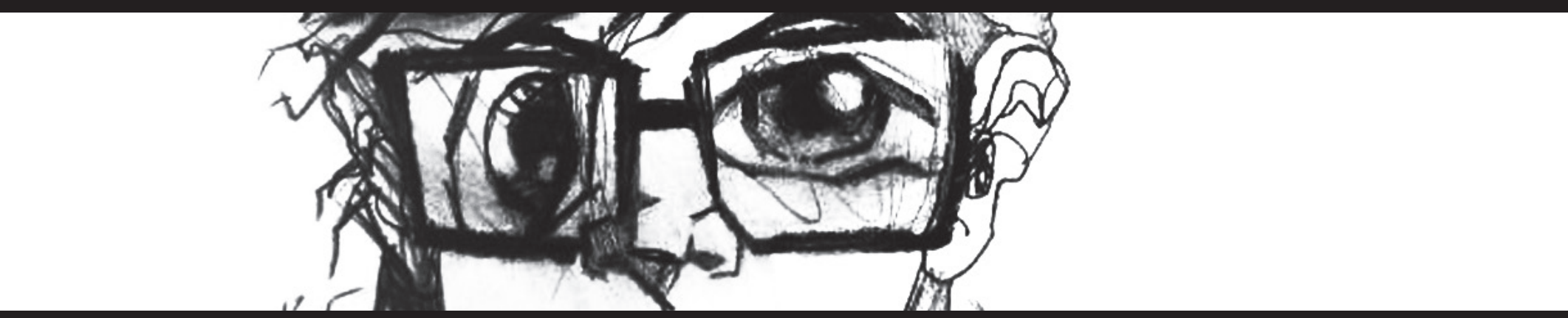




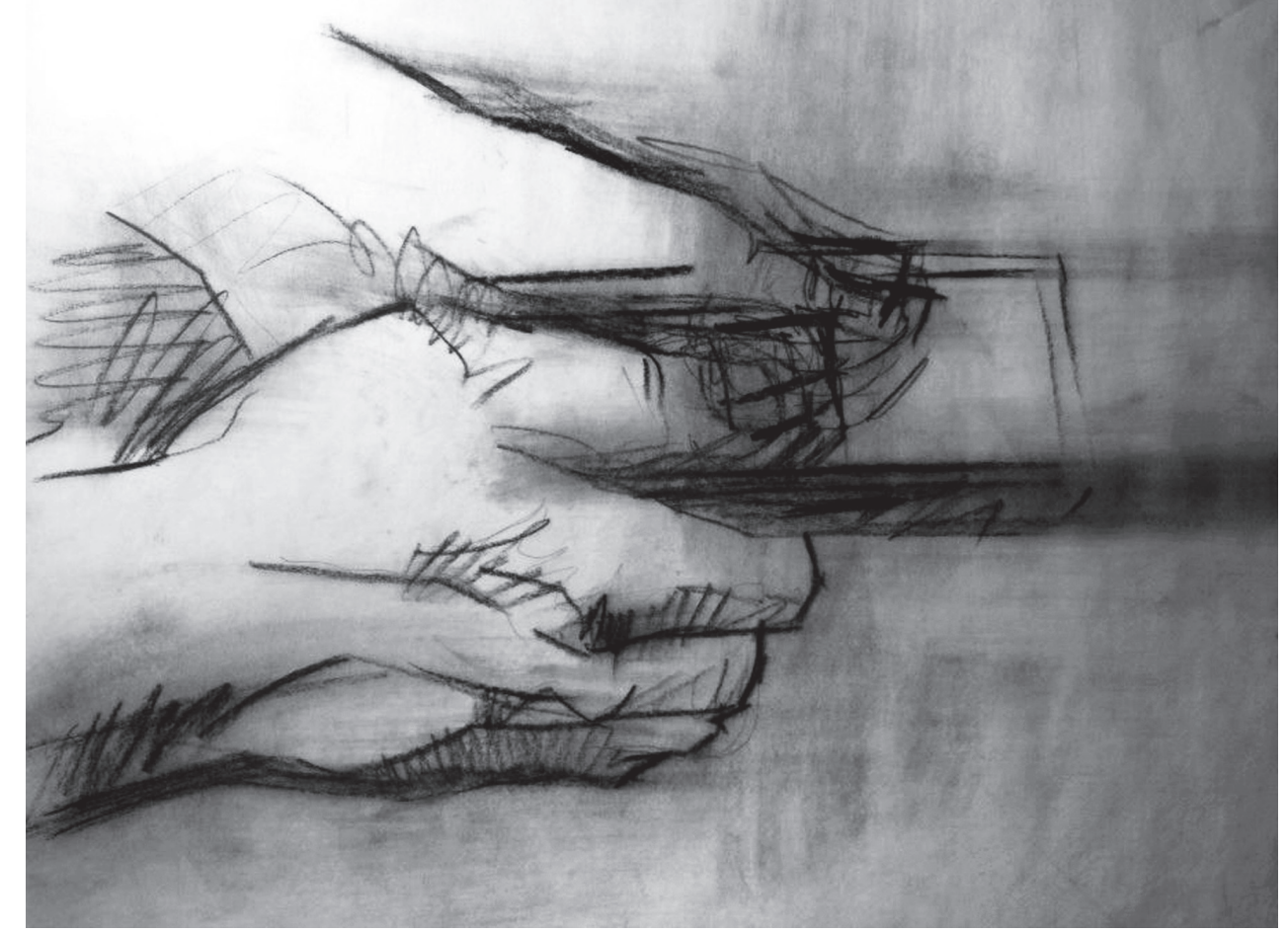

${ }^{11}$ En un sentido general, el canon hegemónico de la escritura alfabética occidental es la forma como se reglamentan los modos de producir textos escritos. Está regulado por la norma lingüística y social, es decir, por una gramática y una pragmática dotada de sus respectivas instancias de control y fiscalización (las academias de la lengua, los científicos o comités editoriales de los periódicos y revistas, los jurados de tesis). Uno de los factores que han determinado la existencia del canon, es la naturaleza misma de la enunciación escrita, que se caracteriza por una doble ausencia: la del lector cuando el autor escribe y la del autor cuando el lector lee. En estas condiciones, es necesario que el autor realice una doble representación verbal en el texto: por una parte, el autor se representa a sí mismo mediante los pronombres personales u otros marcadores deícticos que constituyen la figura del enunciador responsable del enunciado. De igual manera, al escribir, el autor establece otras marcas que orientan al lector sobre el modo como debe tomar los enunciados (si en sentido literal o metafórico, si como afirmación o como pregunta, si como copia literal o como paráfrasis de otro texto, si como verdad o como ironía, si como adhesión a un punto de vista referido o como confrontación del mismo). Por otra parte, el autor eventualmente puede representar verbalmente al lector utilizando los pronombres de segunda persona y otros deícticos que constituyen la figura del enunciatario, es decir, de aquel a quien se dirige en su discurso, conocido comúnmente como “destinatario” (Ulloa y Carvajal, 2006).

${ }^{12}$ La adscripción a la cultura escrita por parte de los integrantes de una sociedad tiene al menos dos implicaciones interdependientes: por un lado, el dominio del canon a partir de una intensa relación con la escritura y la lectura; y por otro, la inserción en una tradición donde leer y escribir constituyen prácticas fundamentales en la vida cotidiana de sectores de la sociedad para los cuales la presencia del texto (manuscrito, impreso o electrónico) y sus usos intelectuales, tienen un alto valor práctico y simbólico. Caso contrario al de aquellas personas que no han desarrollado las mismas competencias ni requieren de la lectura y la escritura para su desempeño social. Ahora bien, la cultura escrita se refiere no sólo a la lectura y a la escritura sino a las relaciones entre éstas y el conocimiento; tanto el conocimiento que se requiere para poder leer y escribir como el conocimiento que se deriva de tales actividades (Ulloa y Carvajal, 2006).

${ }^{13}$ Dicha investigación fue finalizada en el año 1999, al interior de la maestría en Comunicación y Diseño Cultural de la Universidad del Valle, y publicada posteriormente por el Programa Editorial de la misma universidad.

${ }^{14}$ Digo "en ese momento" porque uno de ellos posteriormente empezó a realizar prácticas escriturales y audio-visuales que se asemejan a lo descrito por algunos de los jóvenes entrevistados en Secretos Mutantes. Este joven, es, además, miembro y estudioso -desde la Comunicación Social-, de las Brava Barón Rojo de la ciudad de Cali. 
${ }^{15}$ A diferencia de términos como "joven” y "juventud”, determinados por la edad según criterios que difieren de un país a otro, la categoría conceptual "condición juvenil” está orientada a la comprensión analítica de un segmento poblacional no definido por aspectos psico-biológicos. Formar parte de la "condición juvenil" está determinado por dos rasgos: el vivir intensamente y el experimentar libremente. La condición juvenil no tiene edad; es decir que ser "joven" según la edad cronológica no significa encontrarse en condición juvenil. La condición juvenil se construye subjetiva, social y culturalmente, con los pares y en espacios no institucionalizados como la calle y más recientemente en las redes sociales. Retomo este planteamiento de lo expuesto por Germán Muñoz en el Seminario Culturas Juveniles, en el Doctorado de Ciencias de la Educación, Pereira, 2012.

${ }^{16}$ El proceso de escolarización está orientado a: el disciplinamiento social; la racionalización; la definición de lo que significa ser niño, ser joven y ser maestro; la implementación de la lógica escritural; la anulación de los modos de educación provenientes de otras formas culturales; la definición de un espacio público nacional y la formación de ciudadanos. La institución escolar se encarga de la producción de un orden social y de la reproducción de las estructuras y organizaciones sociales modernas existentes. Como parte de la cultura escolar, se produce un disciplinamiento de los sujetos y de los saberes que implica desplazar las formas desordenadas de la cotidianidad, y se desconocen aquellos saberes propios de las culturas populares para privilegiar la cultura letrada. La escolarización promueve el saber lógico y racional (contrario a los saberes y acciones populares que son diversos, desordenados y “confusos") y se desprestigian las tradiciones y visiones del mundo ligadas al pasado de las regiones y presentes en la memoria (Huergo y Hernández, 1999, capítulo 3).

${ }^{17}$ Aunque todo acto de consumo es en sí mismo una práctica cultural y por lo tanto la expresión 'consumo cultural' resulta altamente redundante, en la investigación Lecturas y Escritura Juveniles (Carvajal, 2008) se utiliza esta denominación, por cuanto interesa hacer referencia explícita al consumo de bienes culturales o simbólicos, tales como: programas de radio y televisión, diarios, libros, revistas y otros materiales impresos, discos, textos electrónicos de diverso tipo, exposiciones, conciertos, películas de cine, videos y representaciones de artes escénicas, producidos por instituciones y actores de la cultura especializada, así como otro tipo de bienes simbólicos generados al interior de dinámicas locales de comunicación, como podrían ser las diversas expresiones de la cultura popular, las programaciones culturales al interior de la vida universitaria, etc. Como puede apreciarse, el término 'cultura especializada' no alude de manera exclusiva a la alta cultura, sino que, además de incluirla, la sobrepasa, pues comprende fundamentalmente los productos elaborados por las denominadas industrias culturales. En cuanto a la noción de prácticas de producción cultural, alude a la puesta en ejercicio de competencias particulares para la producción de bienes simbólicos como: la literatura, el cine, las artes plásticas, el ballet, la música, el teatro, pero también la narración oral, la escritura no literaria, la fotografía, la caricatura, el grafiti, el video, la música folclórica y popular, la artesanía, el arte callejero, la danza, el humor, en fin, cualquier práctica que implica la presencia de actores sociales en un contexto social y en un espacio de interacción y de comunicación concretos. 


\section{Referencias}

Carvajal, G. (2008). Lecturas y escrituras juveniles: entre el placer, el conformismo y la desobediencia. Cali: Programa Editorial Universidad del Valle.

Carvajal, G. (2010). La lectura y la escritura como prácticas de producción y consumo cultural. Cinco premisas para el trabajo pedagógico en la Universidad. En E. NARVÁEZ CARDONA (coomp.), Docencia Universitaria. Lectura y Escritura Académicas (págs. 201-217). Cali: Universidad Autónoma de Occidente.

Huergo, J. A. (1999). Cultura escolar, cultura mediática. Intersecciones. Bogotá : Universidad Pedagógica Nacional.

Lévy, P. (2007). Cibercultura. La cultura de la sociedad digital. Barcelona: Antropos.

Lévy, Pierre. (1999). Cibercultura y educación. En La Universidad en la Sociedad de la Información. Documentos Columbus sobre gestión universitaria. Documento en versión digital.

Marín, M., \& Muñoz, G. G. (2002). Secretos de mutantes. Música y creación en las culturas juveniles. Bogotá: Siglo del Hombre Editores.

Ulloa, A., \& Carvajal, G. (2006.). Cultura escrita, conocimiento y tecnocultura. El marco teórico de una investigación exploratoria en la Universidad del Valle. Revista Nexus Escuela de Comunicación Social Universidad del Valle, $\mathrm{N}^{\circ} 2$, 105-141.

Recibido: Abril 15 / Aprobado: mayo 25 de 2014

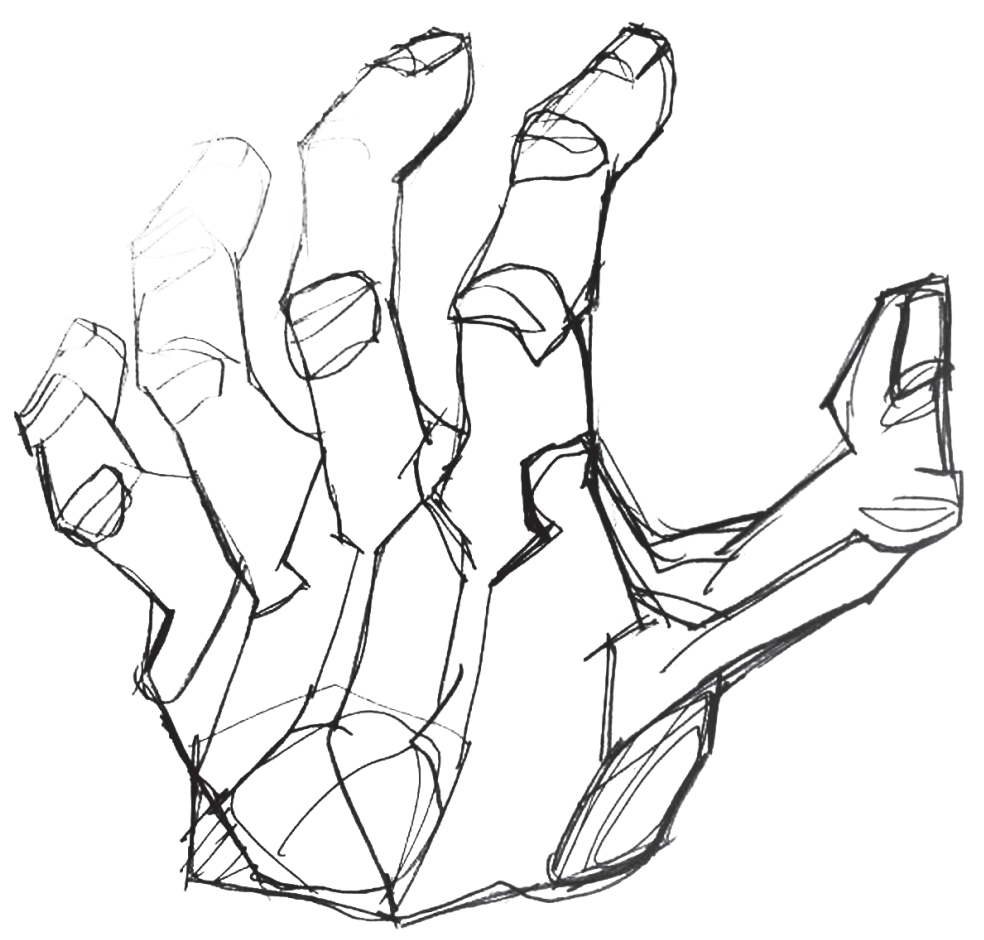

